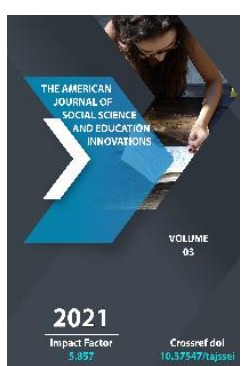

\section{External Sources Of The Development Of The Ethnographic System Of Terms And Internal Resources Of Their Education}

\section{Xodjaeva Nargiza}

Lecturer, Department Of Metodology Of Russian Language, Ferghana State University, Uzbekistan

\section{Viktoriya Gimadetdinova}

Lecturer, Department Of Metodology Of Russian Language, Ferghana State University, Uzbekistan

\title{
ABSTRACT
}

The article considers the specific features of the national language, which record the unique sociohistorical experience of a certain national community of people, as well as the principle of nomination as a kind of rule formed as a result of the generalization of motivated features in the "speaking" team

\section{KEYWORDS}

Ethnography, linguistic picture of the world, the principle of nomination, the space of meanings

\section{INTRODUCTION}

Ethnography (from the Greek eunoz-people and grafein-to write) is a science that studies the culture of peoples. Such a science is quite possible and necessary, but with the current specialization of the sciences, ethnography is forced to limit itself to limits, otherwise it would have to take on the tasks of a number of already established sciences, such as history, psychology, statistics, law, comparative linguistics, etc., which is absolutely impossible with the current growth of purely special tasks of ethnography, which in turn require independent differentiation into special disciplines. Others do not want to recognize ethnography, at least formally, as an independent science, considering it an integral 
part of the unified science of anthropology. This is the attitude of many in England (for example: Tylor), followers of Weitz in Germany, in Russia Professor Petri, Krzywicki, in France the Brock school. [1, p. 236]

The role of language is not only in the transmission of the message, but primarily in the internal organization of what is to be communicated. There is a kind of "space of meanings" (in the terminology of A. N. Leontiev), i.e., the knowledge of the world fixed in the language, where the national and cultural experience of a particular linguistic community is necessarily interwoven. The world of speakers of a given language is formed, i.e., the world of speakers of a given language. language picture of the world as a set of knowledge about the world, captured in vocabulary, phraseology, grammar.

\section{THE MAIN FINDINGS AND RESULTS}

The term "linguistic picture of the world" is nothing more than a metaphor, because in reality, the specific features of the national language, in which the unique socio-historical experience of a certain national community of people is recorded, create for the speakers of this language not some other, unique picture of the world, different from the objectively existing one, but only a specific color of this world, due to the national significance of objects, phenomena, processes, selective attitude to them, which is generated by the specifics of the activities, lifestyle and national culture of this people.

When studying ethnographic vocabulary in such lexical and semantic groups, it is possible to establish the natural conditions in which the life of the people took place, its main occupations, features of the economy, housing, ancient beliefs, and the psychology of the people.

The reasons and conditions that contribute to the archaization of lexemes have received a lot of attention in the scientific literature. It is noted that "the departure of some words from the active stock to the passive stock is due to extra-and intra-linguistic reasons" [2, p. 22]. On the one hand, the number of "social factors affecting the development of the vocabulary of the language as a whole is huge", one of the external factors of updating the vocabulary of the language is the" language taste "of the speaker, the increasing linguistic needs of native speakers, or the desire to" replace the names associated with the old ideology, methods, institutions, officials of the former political system, with new words reflecting a new ideology, a new political system", "update the content of the word in connection with a new understanding of phenomena. On the other hand, the obsolescence (archaization) of words is a natural tendency of each language to get rid of redundant lexical units [3, p.17]. However, " external conditions often create only an incentive for vocabulary change, and the mechanism of lexical transformation itself is determined by the action of intra-system relations between dictionary elements. Often, the reasons for the archaization of words in many cases remain unclear. Their establishment is "a very difficult matter, for these reasons must be determined for each word, or at best for a group of words."

It is necessary to explain some concepts and terms related to the nomination issues that we use in this study.

The nomination principle is a kind of rule that is formed as a result of the generalization of 
motivated features in the "speaking" team. This is the source base for new names.

Thus, the principle of nomination is a significant, meaningful category that is fixed in the minds of people. The method of nomination is the method by which the principle of nomination is implemented. The method of nomination is a kind of form and corresponds to the principle of nomination, both with content and expression. There are two different ways of nomination: direct and indirect. In the first case, the motivation is expressed directly, by the root morpheme of the word, and in the second - associatively, by comparing it with an existing unit.

For the nomination, it does not matter whether the selected feature is significant or not - it is important that this feature is relevant to this subject. That is why the etymology of the word is sometimes based on an insignificant sign from the generally accepted point of view. Now it is difficult to imagine what the word was based on: an object or a feature.

Thus, " ... the language seeks to eliminate the danger of a false characterization of the meaning of a word, which may arise from the fact that the name is based on the name of a single feature, while the real meaning is based on the sum of the features."

Due to the fact that the choice of a feature for the name is not determined by laws, this choice is arbitrary, in linguistics, the thesis about the random nature of the nomination was formulated. "The choice of the very attribute of the so-called fact of reality, which is the basis of the name, turns out to be arbitrary, or rather, more or less random, depending on the degree of materiality."
This thesis is usually used to explain the differences in the name of the same object in one or different languages. Very often, there is a coincidence of the motivating feature in different and even genetically distant languages. This is due to the similarity of a huge social practice, which allows people to distinguish from the mass of signs one and the same and put it as the basis for the act of nomination.

\section{CONCLUSION}

"The situation in the first case is called semasiological analysis, the situation in the second-onomasiological analysis." This was once pointed out by Fr. Jespersen. In his opinion, every linguistic phenomenon must be considered either on the basis of its external form, or from its internal meaning. In the first case, we go from the form to the meaning, in the second, " we go from the meaning and ask ourselves what formal expression this meaning finds in this particular language."

Based on the material of the units of ethnographic vocabulary studied by us, it can be noted that in the semantics of specifically objective nouns, the closest connection of the lexical meaning of a word with the specific properties of reality is observed.

Thus, the main motivating feature of the ethnographic vocabulary in the Russian language is an indication of the purpose for designating the process.

\section{REFERENCES}

1. Baskakov N. A. Ethnographic vocabulary and terminology in national Russian dictionaries / / Problematika opredeleniy terminov v slovariyakh razlichnykh tipov. JL, 1976. - p. 236. 
2. Adilova G. A., Suatay S. K. Ethnographisms as a reflection of the relationship between the history of language and culture// Russian language and culture in the mirror of translation: mat-ly mezhdunar. konf. 2530 April 2014: e. ed. - Moscow: Moscow University Press, 2014. - p. 22.

3. Akhmanova O. S. Dictionary of linguistic terms. - Moscow, 2004.

4. Khamidov Kh.Kh., Ismatullayeva N.R., Rasulova Z.Kh., Karimova D.E. The Issues of Word Choice in Fiction Translation. International Journal of Psychosocial Rehabilitation, Vol. 24, Issue 04, 2020. - pp. 6660-6668. DOI: 10.37200/IJPR/V24I4/PR2020478 